\title{
O CARNAVAL DOS ANOS TRINTA E A SUPOSTA "CRISE" CARNAVALESCA FEIRENSE ${ }^{12}$
}

Recebido em: 21/08/2019

Aceito em: 02/02/2020

\author{
Miranice Moreira da Silva ${ }^{3}$ \\ Universidade do Estado da Bahia (UNEB) \\ Santo Antônio de Jesus - BA - Brasil
}

\begin{abstract}
RESUMO: O artigo discute a narrativa da "crise" carnavalesca feirense dos anos de 1930 e tem o objetivo de compreender como as representações sobre a festa revelam os projetos de sociabilidade e de um imaginário de cidade pautados nos ideais de modernidade. Para alcançar esse objetivo optei por um aporte teórico que pensa as cidades como resultado de construções coletivas que, para além da materialidade, considera as sociabilidades e sensibilidades (PESAVENTO, 2007). E nesse aspecto penso que as representações (CHARTIER, 1990) são partes fundamentais na construção dos imaginários (BACZKO, 1985). Essa análise foi fundamentada na interpretação das fontes jornalísticas, que entendo terem sido fundamentais na construção de um ideal de festa e da cidade. Isso porque não considero os jornais como apenas veículos de notícias e sim como espaços de poder e de construtores de sentidos (CHAUÍ, 2006).
\end{abstract}

PALAVRAS-CHAVE: Carnavais. Sociabilidades. Cidades.

\section{CARNIVAL OF THE THIRTIES AND THE SUPPOSED CARNIVAL "CRISIS" FEIRENSE}

ABSTRACT: The article discusses the narrative of the carnival feirense of the 1930s and aims to understand how the representations about the party reveal the projects of sociability and an imaginary city, based on the ideals of modernity. In order to achieve this goal, I opted for a theoretical approach that considers cities as the result of collective constructions that, in addition to materiality, consider sociability and sensibility (PESAVENTO, 2007). In this respect I think that representations (CHARTIER, 1990) are fundamental parts in the construction of the imaginary (BACZKO, 1985). This analysis was based on the interpretation of journalistic sources, which I believe were fundamental in the construction of a party and city ideal. This is because I do not consider newspapers as just news vehicles, but rather as spaces of power and sense builders (CAHUÍ, 2006).

\footnotetext{
${ }^{1}$ Trabalho financiado pelo Conselho Nacional de Desenvolvimento Científico e Tecnológico (CNPq)

2 Artigo Selecionado no Simpósio Temático "História do Lazer e dos Usos Sociais do Tempo Livre", realizado no $30^{\circ}$ Simpósio Nacional de História.

${ }^{3}$ Doutoranda em História pela Universidade de Brasília. Docente da Universidade do Estado da BahiaCampus V. Integrante do grupo O Som do Lugar e o Mundo“ da UFBA.
} 
KEYWORDS: Carnivals. Sociability. Cities.

\section{Introdução}

O presente artigo tem por objetivo discutir como as narrativas construídas sobre os festejos carnavalesco revelam formas de ver, sentir e viver a cidade e compreender como o lazer é apropriado como elementos na construção de imaginários. Trata-se de um artigo fruto da dissertação de mestrado Entre máscaras e serpentinas: por uma história dos festejos carnavalescos feirenses (1891-1939), que para essa publicação sofreu revisão, sobretudo teórico-metodológicas. E para fazer sentido o debate sobre as “crises" carnavalescas precisamos recuar um pouco mais para compreender o contexto carnavalesco feirense e brasileiro, aliados aos projetos de sociabilidade moderna.

Os festejos carnavalescos em Feira de Santana-Ba datam desde os últimos anos do século XIX, conforme os dados que encontrei em jornais da cidade e em um inventário produzido por Helder Alencar (1968); em uma edição comemorativa de 31 anos da micareta.

Ao longo dessas experiências carnavalescas a cidade pode contar com três formas de viver o carnavalesco: entrudo, carnaval e micareta. Não as classifico como festas absolutamente distintas, por isso as coloco em uma mesma categoria; festas carnavalescas por manterem uma mesma estrutura.

Entretanto para que possam compreender do que se trata esse artigo, preciso recuar um pouco para primeiro explicar a relação entre entrudo e carnaval para depois chegarmos a definição da micareta. O Entrudo e o Carnaval consistiam na prática de sair às ruas três dias antes da Quaresma e assim despir-se dos prazeres da carne antes que o período de recolhimento espiritual, sugerido pela tradição cristã católica começasse. Ocupar as ruas em um divertimento coletivo, molhando e sujando as 
pessoas enquanto o riso, a música e a dança libertavam os corpos. Partindo dessa lógica carnavalesca de elevação da cidade a um estado de liberdade social, não haveria motivo algum para que hierarquias e classificações da forma de viver o carnavalesco fossem construídas.

Entretanto, conforme afirma Bakhtin (2013) o carnaval é o segundo mundo, uma segunda vida; pois durante os festejos o mundo de quem festa e nele está envolvido de alguma outra forma ganha outras tonalidades, mas isso nada mais é do que a vida teatralizada, nas palavras de Bakhtin (2013). Isso significa que os sentidos e significados de uma estrutura social não desaparecem nos dias de Momo; elas estão lá e a criação dessas classificações e representações da festa são construídas a partir do mundo que constrói a festa.

E é a partir dessa lógica, de que não há uma ruptura total dos dias ordinários, que se construiu a diferença entre carnaval e entrudo. Nesse momento retomo a contribuição de Kosselek (2006) que em suas pesquisas sobre história dos conceitos aponta para o fato de que as construções de nomenclatura não significam apenas uma construção normativa da palavra; elas carregam consigo os sentidos e uma ideia que ao ser concretizada em palavra traduz uma interpretação um pensamento que significa e classifica aquilo que está sendo nominado.

Com o estabelecimento de duas palavras para classificar práticas carnavalescas, que até meados do século XIX não eram vistas como coisa diferentes exemplifica bem esse pressuposto. Segundo Maria Clementina Cunha (2001) a diferença entre carnaval e entrudo, foi estabelecida a parir de um ideal que queria separar por classes os grupos que festejavam e a partir disso crias representações do que seria adequado e o inadequado, a partir de uma lógica da modernidade. A partir dos estudos de Cunha 
(2001) O entrudo seria fruto de práticas arcaicas, oriundos de classes populares e negros e negras libertos. Em oposição representativa a isso estava a ideia de carnaval veneziano, civilizado, praticado por uma sociedade moderna. Mas é claro que essas delimitações não eram tão rígidas assim; o trânsito entre essas modalidades existia, seria um erro tratar de práticas culturais de forma tão cartesiana. Cunha (2001) relata a presença de grupos das elites entre os brincantes do entrudo, por exemplo.

Mas o que nos interessa nesse aspecto é perceber que a diferenciação entre entrudo e carnaval foi criada a partir da construção de significados, que pautado na classificação dos grupos que as praticavam, colocou em oposição entrudo (bárbaro) e carnaval (civilizado). Se formos observar as práticas, diferenças muito poucas: ambas sujavam e molhavam as pessoas; uns com pós de mico e águas das mais diversas, outros com serpentinas e águas de cheiro (SILVA, 2013). Se você perguntar se há diferença molhar alguém com água fétida ou alfazema, a resposta é simples: claro que sim! Mas no entrudo não se sujavam a todos pós e odores desagradáveis. A escolha dos alvos era fundamentada nos conflitos do dia a dia. E nesse ponto resistia o risco de um lazer tão liberto. Estariam os fazendeiros e patrões do final do século XIX e início do século XX à vontade para festejar junto as mais variadas classes sociais, onde as ruas modernizadas poderiam tornar-se quadrados da subversão?

A diferença entre carnaval e entrudo, inventada em um Brasil recém republicano da coisa pública, que na perspectiva de Hannah Arendt (2016) não significa um mundo igualitário, fazia parte de um projeto normativo de costumes. E é dentro dessas tentativas, em que o lazer é usado em um projeto de cidades e sociabilidades, que encontro nos festejos carnavalescos feirenses das décadas de 1930 uma mesma preocupação normatizadora de hábitos (BOURDIEU, 2002). 
Entretanto, retomando as ideias de Roger Chartier (1990), as representações são construídas a partir de disputas; que envolvem conflitos e também negociações para que possam se estabelecer efeitos de verdade. E a partir desse mundo de construções representativas, que recortei para o esse artigo justamente o momento de indecisões e arranjos representativos que para além das festas também ajudam a compor um imaginário (BACZKO, 1985) de cidade hábitos.

Esse artigo busca problematizar como as construções narrativas festivas do jornal ajudam a compor uma imagem de sociabilidades urbanas que na perspectiva de Sandra Pesavento (2007), nada mais é do que a forma como as pessoas vivem a cidade. Sociabilidade que está envolta das sensibilidade de sentir a materialidade das ruas, avenidas e praças; elementos que tornam a cidade legível.

E esse momento de transições: entre uma busca pelo carnaval civilizado e as “crises" do carnaval que surgiu a Micareta de Feira de Santana: um carnaval temporão que deu à Feira de Santana o título de inventora de carnaval fora de época ${ }^{4}$. A diferença fundamental entre a Micareta e o carnaval é a mudança de data, pois é realizada sempre depois do domingo de páscoa. Nesse artigo a Micareta aparece como uma solução às “crises" carnavalescas de Feira de Santana.

E é disso, das "crises" do carnaval feirense e de seus significados que passamos a falar a partir de agora

\footnotetext{
4 Título que é disputado com a cidade de Itabuna (SANTOS, 2004), que realizava Mi-caremês; um denominação francesa para comemorações carnavalescas pós quaresma, que em Feira de Santana também eram realizadas, só que inicialmente com o nome de pascoela carnavalesca, e que depois adotou o nome francês e em seguida assumiu o nome que perdura até os dias de hoje, Micareta (SILVA, 2013).
} 


\title{
A "Crise" Carnavalesca
}

A partir da década de 1930 os festejos carnavalescos passaram a ser noticiados em um contexto de “crise". A referida crise, segundo Helder Alencar (1968), estaria ligada à construção da Rodovia 324, que ligam as cidades de Feira de Santana e Salvador. Porém não seria seguro afirmar que a construção de uma rodovia esvaziaria uma cidade a ponto de não existir o carnaval, pois a criação de infraestruturas para locomoção não garantiria a pronta mobilidade, ou despertaria o súbito desejo por ir ao carnaval da capital.

Essa teoria da "crise" carnavalesca aliada à concorrência com o carnaval de Salvador fomentado pela construção da rodovia, também foi levantado por Aldo Silva, quando afirmou. Em princípio, a teoria da "crise" carnavalesca em Feira de Santana esteve fundamentada na concorrência com o carnaval de Salvador, que teria sido fundamentada pela construção da rodovia, aspecto que foi abordado por Aldo Silva:

\begin{abstract}
A abertura da rodovia concluída em 1929 criou a possibilidade, portanto, de os feirenses desfrutarem do carnaval em Salvador. Em 1932 essa prática já se mostrava em franca expansão, com a população preferindo a festa na capital, de modo que Feira de Santana via-se progressivamente esvaziada de seus foliões, fato, aliás, claramente percebido pelos munícipes de então, para os quais o carnaval daquele ano havia sido apenas 'modesto' (SILVA, 2008, p. 122).
\end{abstract}

O dado sobre a facilidade do trânsito entre Feira de Santana e a capital é inegável, porém esse fator não foi determinante para a chamada "crise" carnavalesca, pois muito antes de 1929, ano de conclusão da rodovia Br. 324, alguns grupos, em especial as filarmônicas, já promoviam passeios à capital durante os festejos carnavalescos. Como já foi citado anteriormente, e retomo neste momento como um 
caráter demonstrativo, os passeios eram uma prática comum durante o período carnavalesco:

\author{
Passeio à capital. \\ Conforme se vem anunciado, realisa-se nos vindouros dias 21, 22 e 23 \\ o passeio de recreio à capital do Estado, promovido pela Sociedade 25 \\ de Março. \\ Partindo desta cidade às 22 horas de 21 chegarão os passantes à cidade \\ do Salvador às 8 horas da manhã seguinte, estando-lhes preparados \\ pomposa recepção, promovida pela colônia feirense e pela sociedade \\ Recreio do Bomfim e Muturia dos Musicos do $1^{\circ}$ grupo da polícia. \\ Nessa recepção tomarão parte várias corporações orpheicas bem como \\ Recreio do Pilar e Lyra de Appolo e Carlos Gomes Lyra de S. Braz \\ (FOLHA do NORTE, 1914, n. 209).
}

Não se pode negar que havia migração de grupos para o carnaval, mas como vimos no fragmento anterior, isso ocorria muito antes da inauguração da Br. E nesse aspecto e questionar quem são esses sujeitos que migram para o carnaval soteropolitano. E nisso Aldo Silva avança no debate e dá indícios para essa interpretação

O êxodo dos foliões, especialmente daqueles tidos como "influentes", determinou a derrocada do carnaval feirense. As figuras mais abastadas e destacadas preteriam a festa local em favor dos festejos na capital, influenciando assim boa parte da comunidade, que seguia o mesmo caminho (SILVA, 2008, p.123).

O chamado êxodo não era algo que promovia o esvaziamento da cidade, apenas alguns grupos, por sua questão social vantajosa, que tinha acesso ao carnaval soteropolitano. A concorrência com o carnaval de Salvador é anterior à construção da rodovia. O que mudou foi a forma como essas alternâncias, entre carnavais mais expressivos e os menos entusiasmados, passavam a ser tratados pelos veículos de informação. E pensando o papel discursivo da imprensa na construção das festas, discordo da afirmativa que responsabiliza o fim do carnaval apenas a saída de grupos influentes da cidade. Aliado a isso, entendo que a construção desse "enfraquecimento" 
esteve ligado a uma eficiente narrativa, que além de difundir a ideia da "crise" carnavalesca, silenciavam as práticas carnavalescas, daqueles que não pertenciam a porção elitizada da festa.

Esses silêncios, segundo Eni Orlandi (2007), ajudam a compor uma narrativa que coloca o protagonismo dos desfiles primeiro em um grupo social e em segundo em outra cidade. Discurso que consegue atravessar o tempo e se faz presente nos anos de 1980, com o edital comemorativo dos 50 anos de micareta.

Nisso a Revista Panorama da Bahia ajudou no debate dessa problemática, pois quando a Micareta completou 50 anos de existência foi lançado um número comemorativo que se prestou a fazer um dossiê e nele apareceu o seguinte dado:

Folião solitário: Na realidade, Feira de Santana passou a viver grandes festas momescas a partir da criação da Mi-carême. Manoel Fausto dos Santos, ex-jogador de futebol e desportistas amador conhecido como "Mané de Emília", com 87 anos de idade, lembra-se perfeitamente que o Carnaval em Feira de Santana começou a existir em 1929. O comerciante Antônio Azevedo, filho de Feira, mas residente no Rio de Janeiro, ficou decepcionado quando resolveu vir passar o Carnaval na terra natal em 29. A festa simplesmente não existia. "Ele então me incentivou a estimular a realização da festa, consultamos vários intelectuais que na época trabalhavam na "Folha do Norte" e o primeiro resultado prático foi a fundação do "Clube Carnavalesco as Melindrosas" em 4 de fevereiro de 1929, da qual fui presidente por Vários anos (REVISTA PANORAMA da BAHIA, 1987, n. 80, p. 12).

Na conclusão da revista, é estabelecido que a micareta teria sido a responsável por colocar fim na crise carnavalesca que se abatia sobre a cidade. Para validar esse discurso recorreram ao Mané de Emília, um dos criadores do Clube Carnavalesco Melindrosas; que entre as décadas de 1930 e 1940 foi um dos maiores destaques das festas carnavalescas em Feira de Santana. Grupo que também se fazia presente em outros momentos de lazer da cidade, a exemplo da Festa de Santana e das partidas de futebol da cidade. 
A memória trazida com a entrevista afirma que o carnaval em Feira de Santana passou a existir em 1929, o mesmo ano de fundação da Melindrosas. Talvez a memória de Mané de Emília quisesse enfatizar o protagonismo desse grupo festa ou também sua memória não considerasse aquilo que era praticado antes de 1929 como sendo a prática do carnaval. Acredito que as duas possibilidades se fundem, pois a década de 1920 e metade da década de 1930 foi marcado nos jornais pelo combate da prática do entrudo. E sobre esse período que antecede a criação do Clube, "quase que não existia carnaval”. Nessa leitura, as Melindrosas teriam consolidado esse carnaval.

O dado acima também diz que a partir de uma comparação com o carnaval carioca, que na ocasião era a capital do país, surgiu uma reformulação dos festejos com o envolvimento de um dos principais jornais da cidade, o Folha do Norte. Esse fator explica o porquê da riqueza dos detalhes do referido jornal ao documentar e divulgar a festa a partir de 1930. A comparação com o carnaval carioca aponta para uma busca de ideal carnavalesco, que nessa narrativa coloca tudo que nele não se encaixe como algo a ser superado.

Compreendo que essa ênfase no ano de 1929 funciona como uma forma de fazer esquecer as práticas ditas incivilizadas do entrudo. Nesse aspecto é importante retomar os estudos de Maria Clementina Cunha (2001), que analisa como se deu a construção da diferença entre o entrudo e o carnaval. Partido do estudo de caso do carnaval carioca na passagem do século XIX para o século XX, a autora chega à conclusão de que essa foi uma diferença fundada a partir dos significados atribuídos a tais práticas carnavalescas que estiveram aliadas a um projeto modernizador das cidades. Segundo a autora, até meados do século XIX não existia diferença entre eles, entrudo era carnaval. A autora 
identifica que o combate ao entrudo acontece ao mesmo tempo em que ocorrem a fundação das grandes sociedades e se intensificou a partir de 1880 .

Não por coincidência esse período corresponde às políticas abolicionistas: "Exibindo características africanas no momento em que a luta pela abolição do trabalho escravo estava bem via, os negros dos cucumbis encontravam certo grau de tolerância no interior da festa" (CUNHA, 2001, p. 43). O risco da liberdade das "classes perigosas" como diria Sidney Chalhoub (1996) nas ruas, dividindo o mesmo espaço de lazer e festejando era algo que colocaria em risco as fronteiras sociais. Então através de uma construção narrativa, na qual os jornais foram peças fundamentais, o entrudo, como uma prática mais simples e jocosa de festejar os dias de Momo, passou a ser associado às populações negras e pobres, que no final do século XIX era associada à um passado monárquico que deveria ser superado. E a solução para isso era a construção significativa de um carnaval civilizado que faria jus a práticas culturais de um país moderno, onde não bastava apenas reformar as ruas, mas também os hábitos. E a partir desse projeto "Ao carnaval veneziano, associado à superioridade presumida das cores claras, cabia a tarefa de iluminar as ruas e as "massas", guiando-as para outro patamar de civilização". A partir dessa interpretação, entendo que as práticas culturais funcionavam como um espaço para educar a sociedade segundo os hábitos visto como adequados, e isso se faz a partir da valorização de comportamentos e depreciação de outros, que por vezes ocorria pelo silenciamentos.

Assim como aconteceu em Feira de Santana, a palavra entrudo desapareceu dos noticiários cariocas, sendo colocados apenas como praticas "inadequadas", "rudes" e “selvagens". Assim como não foi mencionado nas memórias de Mané de Emília, o silêncio sobre a prática caracterizada como entrudo, ela em consonância com uma 
construção narrativa que vê o carnaval como uma forma adequada e que merece figurar as memórias festivas de uma cidade. (CUNHA, 2001, p. 95)

Contudo, a implantação de uma prática e da construção de significados atribuídos ao lazer não é algo simples, que se estabeleça como um decreto; as pessoas significam o lazer a partir de suas vivências e representações. Logo esse hiato entre o momento em que se lança a representação de uma prática até a sua apropriação (CHARTIER, 1990), é um espaço de imprecisões e possibilidades interpretativas. Nessa lógica habituou-se caracterizar esse período, em que o entrudo não estava vencido, como uma "crise" carnavalesca, na qual era comum buscar culpados para a não realização a contento do carnaval ou ainda a permanência do entrudo entre os hábitos carnavalescos (CUNHA, 2001). E parece-me que esse era o caso de Feira de Santana nas primeiras décadas do século XX; uma crise que se buscava justificava a partir de uma concorrência com o carnaval de Salvador.

E como tentativa de superar essa "crise" na década de 1930 houve um esforço em renovar, "salvar" as festividades carnavalescas, que teria sido o cordão das Melindrosas como uma injeção de ânimo aos festejos carnavalescos. Segundo o dado da Revista Panorama da Bahia, essa iniciativa não teria sido suficiente.

A iniciativa de Antônio Azevedo, apoiada por outros foliões não foi suficiente, entretanto, para fazer com que o carnaval fosse realmente uma festa animada em feira de Santana no período de 29 a 36. "Tanto que em 36 "as melindrosas" foram participar da festa momesca de Muritiba, ocasião em que aconteceu a primeira desavença no clube, tendo como desfecho a criação de um novo clube carnavalesco: Flor do Carnaval (REVISTA PANORAMA da BAHIA, 1987, n. 80, p. 12).

Quando a Revista Panorama da Bahia usou o termo "salvar", a pergunta que surge é de quê? O que ameaçava a festa era apenas a concorrência com o carnaval soteropolitano? Considero o elemento da proximidade com o carnaval da capital baiana, 
mas acredito que para, além disso, a tentativa de "salvar" o carnaval feirense esteve muito mais ligado ao anseio de sufocar práticas e sujeitos indesejáveis. E que as narrativas entorno dessa crise esteve aliado a um projeto modernizador; que nas décadas de 1930 e 1940 foi o grande desafio lançado nas páginas dos jornais feirenses, no qual os festejos carnavalescos deveriam demonstrar como Feira de Santana estava a se modernizar.

E pensando a fragilidade da escolha de um único argumento, o texto apresenta um elemento de que a concorrência com o carnaval de Salvador não teria sido tão decisivo, pois trata de um passeio do Bloco das Melindrosas para a cidade do Recôncavo baiano; Muritiba. Logo a concorrência com outras cidades sempre foi uma realidade, independente da construção da Br. 324. Dessa forma, o suposto esvaziamento da cidade não ocorria só por causa da construção da BR. 324, tendo como destino apenas Salvador, visto que os grupos carnavalescos tinham outros destinos.

Esses são indícios que reforçam a possibilidade interpretativa do fato de a concorrência com outros carnavais terem sido potencializadas em uma narrativa de “crise" carnavalesca para negar aquilo que não se encaixava a um imaginário de lazer que atendesse a anseios modernizadores e civilizatórios.

Essa preocupação em educar uma sociedade a partir de práticas culturais faz dialogar com a interpretação de Norbert Elias (1994). O autor ao pensar o conceito de civilização, na perspectiva francesa, destaca justamente essa preocupação com os costumes das classes médias, que deveriam se assim quisesse ser civilizada, aproximarse dos hábitos de uma elite da corte.

Seguindo essa lógica de consonância com ideais civilizatórios, não por acaso o carnaval de Feira de Santana tinha como trajeto oficial dos festejos a Rua da Direita. 
Tratava-se de um espaço símbolo desses ideais civilizatórios; os limites dessa via pública eram demarcados pela Igreja Matriz e o jardim do Casarão do coronel Agostinho Froes da Mota. Entre esses dois marcos estava a Escola Normal, Filarmônicas (25 de Março, Vitória e Euterpe Feirense) e a Sociedade Montepio dos Aristas Feirenses.

E a partir dessa perspectiva de fomento a um carnaval civilizado e "necessário" para a cidade que uma narrativa passou a ser construída, que falava sobretudo sobre uma sociabilidade moderna atrelada ao carnaval.

E esse movimento apresentou indícios pela metodologia da imprensa, que ajudou a construir um imaginário de festa. $\mathrm{O}$ primeiro dado é que o evento festivo passou a ser noticiado com quinze dias de antecedência e não mais em uma nota de véspera. "O Carnaval avisinha-se: mãos à ombro foliões. Falta apenas uma quinzena para que Momo - o eterno e sempre almejado deus do riso e do prazer - surja, dominador, na urbe feirense, instituindo seu ephemero, mas salutarissimo reinado" (FOLHA do NORTE, 1931, n. 1124).

Cabe analisar nesse momento como aspectos da cultura começaram a ganhar espaço nas páginas dos jornais a partir da década de 1930. Antes desse período as informações que encontradas eram escassas sobre cultura e lazer, sobretudo porque os jornais feirense, à época, tinham uma circulação semanal e no máximo de quatro páginas, a exemplo do Jornal Folha do Norte. E isso não pode ser interpretado sem pensar o movimento de construção de uma identidade nacional varguista; que via na cultura um espaço de difundir um ideal identitário e que encontrava nos jornais esse veículo de fusão de projetos (FAUSTO, 2009). 
E segundo Marilena Chauí (2006), a imprensa se apresenta como essa voz que faz circular uma ideia que é facilmente absolvida, pois é construído sob a falácia da imparcialidade e da ideia de porta-vozes da opinião pública. E as festas carnavalescas funcionavam nas páginas dos jornais como um espaço propício a implantação de uma forma de sociabilidades que seguisse um imaginário de sociedade moderna.

E nessa perspectiva, as notas sobre o festejo cresciam gradativamente à medida que este se aproximava e existia um apelo, uma espécie de justificativa para valorizar o momento:

Todas as classes deveriam, aliás, empenhar-se pelo esplendor do Tríduo da Folia em seu próprio interesse, porque eles iriam aproveitar a circulação do dinheiro que se retrai e até sonega pesar de ser evidente a necessidade da contribuição geral. $\mathrm{O}$ commercio, os profissionais da volante, os artistas de varias espécies, confeccionadores de vestes e artigos apropriados, além de outros têm compensações vantajosas do que por ventura, venham a depender em auxílio às grandes festas locais. A verdade desse assertivo é irrefutável (FOLHA DO NORTE, 1931, n. 1125).

Uma justificativa que atentou para os benefícios econômicos que os comerciantes poderiam ter caso houvesse um empenho para que a festa ocorresse, seria então um bom negócio investir nas festas locais, pois isso só traria benefícios. Havia um trabalho de convencimento da população de que a festa, nos moldes imaginados, era sinal de desenvolvimento da cidade.

E as justificativas seguiram para além do caráter econômico, perpassando como foi citado no capítulo anterior, por uma questão social e segundo a fonte "psycologica". Importância que extrapolava os aspectos econômicos e atingia o "bem-estar social" no qual o carnaval era representado da seguinte forma:

O carnaval é uma festa civilizadora e necessária até do ponto de vista psycologico, 'pois é uma grande válvula de segurança aberta para a expansão do prazer franco a que a vida atctual, a mais torturante (...) 
de todas as epidemias as que menos receio e terrores inspiram é provocar alegria é isto é o carnaval (FOLHA DO NORTE, 1931, n. 1126).

A festa caracterizada como "uma válvula de segurança"; o aspecto do permitido e de um descontrole programado e sob determinado molde. Isso dialoga com a interpretação de Le Roy Ladurie (2002), que identificou essa discurso do permitido dentro de limites temporais e espaciais estabelecidos como uma forma de controlar e evitar insurreições.

E dentro dessa lógica de oferecer uma festa adequada, é que uma vasta e continua política de propaganda antecedia os festejos carnavalescos. Existia uma espécie de preparação com convites à participarem da festa desde a sua organização, com justificativas econômicas e sociais. Nesse contexto é que carnaval de 1931 foi realizado na segunda quinzena do mês de fevereiro e um balanço foi feito pelo jornal Folha do Norte sobre o festejo:

Os brilhos e os delírios de carnaval, nesta urbe notadamente na terçafeira gorda, excederam as previsões optimstas dos próprios momocratas.

A comissão organizadora e executiva do tríduo da alegria está de parabéns pelo êxito de seu louvável emprehendimento resultante de esforços titânicos a supprir a deficiência de numerários.

Porque, em verdade (seja nos permitido a franqueza ao registrarmos os eventos álacres da quadra em que as verdades podem e devem ser ditas) ela não foi auxiliada como merecia (FOLHA do NORTE, 1931, n. 1127).

Os festejos foram realizados, mesmo apresentando um saldo positivo no qual se afirma que as expectativas dos otimistas foram superadas, ao final do balanço deixou transparecer que não alcançou o esperado. Ao mesmo tempo em que faz a afirmativa que o carnaval tinha sido de brilho e delírio, trata de um descontentamento com a festa. Essa cobrança por apoio poderia ser ausência de investimento financeiro e também com 
a possível falta de adesão ao que se entendia enquanto carnaval civilizado. E essa cobrança passou a ser cada vez mais frequentes nos jornais.

Apesar dos anos da década de 1930 serem caracterizados como uma crise carnavalesca, os mesmos veículos informativos apontaram para uma sequência festiva, inclusive foram os anos que se encontraram uma quantidade maior de reportagens sobre o período carnavalesco.

E à medida que os anos avançavam a ideia da crise ganhava mais força, chegando a anunciar prematuramente a redução do brilho do festejo de 1932.

\footnotetext{
Carnaval

Está decretada para mais algumas horas o início do regime oficial da alegria.

Ao poder do eterno deus do riso e da loucura jamais resistiu a gente sadia e moça sem preocupações sem mágoas.

A crise absorvente reduzirá de muito os trilhos e animação do transcorrido triende. Será modesto o tríduo do prazer em 1932. Sob o controle de comissão esforçada, cujas actuação dedicada foi o seu tempo encarado como prodigiosa pelo muito que realizaram, pelo êxito extraordinário de quando empreenderam, o carnaval implantouse victorioso na Feira, com a sua característica de festa typica essencialmente popular (FOLHA do NORTE, 1932, n. 1177).
}

As dificuldades em realizar os festejos poderiam muito bem diminuir o brilho da festa, segundo a versão do jornal, mas não a impediu de ser realizada. Um questionamento é pertinente, seria essa a opinião de todos, será que o brilho deixou de ser intenso para todos ou era essa impressão de um grupo? Não se pode em momento algum perder a dimensão de que a imprensa é um veículo de ideais e que não representava a totalidade muito menos uma unanimidade.

Mesmo apresentando tantas dificuldades, a "crise" não teria sido algo que interrompesse com os festejos, o próprio jornal no ano seguinte acabava corroborando para essa ideia de que a crise era para alguns e não comprometia a todos a ponto de impedir a realização do festejo: “o período é de penúria, de crise de tudo, elle não 
impediu, porém que a alma popular se entregasse às expansões mais vivas e inebriantes, celebrando a festa oficial da Alegria." (FOLHA do NORTE, 1933, n. 1233).

Mas observem que nesse outro fragmento, parecem estar se referindo a uma crise econômica na cidade, provavelmente uma consequência da seca dos anos de 1930 . Esse foi um período que a região nordeste passou por um período de estiagem significativo e que impactou no setor agrícola (NEVES, 2001). E Feira de Santana, por ser um entreposto comercial, sobretudo agrícola, deve ter sentido impacto disso. E nesse aspecto a crise atribuída ao carnaval ganha outro significado apara além da proximidade com Salvador e mostra o quanto ela estava enraizada ao movimento da história.

Os festejos por mais tradicional que possam parecer, sempre estão em constante transformação, seja na mudança de um cortejo ou na introdução de novos elementos e comportamentos. Em uma reportagem, essas mudanças ficam um pouco mais perceptíveis do ponto de vista das práticas.

\footnotetext{
Apresentem-se, foliões!

Mais uma quinzena a decorrer e implanta-se nesta urbe o regime momocratico.

$\mathrm{O}$ eterno deus risonho renuncia jamais o seu pomposo reinado e seus adeptos são incontáveis em todos os centros cultos.

São, muitos muitíssimos os citadinos que anseiam pelo tríduo da folia, em que renovarão as batalhas incruentas a confetes, serpentinas, perfumadores, ou melhor, lança perfumes.

Essas rodas elegantes de mocelinhas jovens e rapazes discutem-se a adaptação de figurinos carnavalescos para os dias 11 e 13 de fevereiro próximo, nos quais além dos corsos e passeatas vespertinas, affectarase-ão bailes a fantasia em várias partes. (...) Haverá surpresa. Dizem-nos que projetam um bloco dos camisas...

Ah! O ledor tem interesse em saber qual o motiz? Com franqueza; ignoramos (FOLHA do NORTE, 1934, n. 1280).
}

A adequação das vestimentas carnavalescas deu o tom de mudanças. Por questões climáticas, as vestimentas daqui deveriam ser adaptadas para um conforto maior. O corso citado na fonte já era algo corriqueiro nos festejos carnavalescos, uma 
espécie de carro alegórico, em menores proporções do que estamos habituados a ver, mais que era sempre decorado com brilho e com alguns personagens em destaque. Permaneceram também os jogos: guerras de objetos e o costume de molhar uns aos outros. Nesse caso específico o uso da serpentina e do lança-perfume.

E mais uma vez o padrão narrativo sobre o carnaval se repete: mesmo mediante uma crise, a cidade não poderia em hipótese alguma renunciar de tal elemento civilizador. Em que o jornal, ao destacar o tipo de acessórios carnavalescos eram permitidos - “confetes, serpentinas, perfumadores, ou melhor, lança perfume” - exerce o seu papel educador na forma de conduzir e orientar comportamentos durante a festa. $\mathrm{E}$ nesse aspecto o silêncio sobre as outras formas de brincar também é uma narrativa, conforme Orlandi (2007).

Mas os interesses dos jornais não são apenas esses, que para além de noticiar e construir representações também funciona como uma empresa voltada para o mercado e o lucro. Após toda a propaganda em torno do festejo, finaliza desta forma:
Aliada uma notícia agradável.
A secção de papelaria da Folha do Norte está devidamente apparelhada para fornecer a todos os momophilos a preços convidativos, máscaras, cabeleiras, barbas, toda espécie de disfarces, ornamentos de vários materiais divertidíssimos feito em summa. Uma complexidade admirável de artefactos carnavalescos que incomparável indústria allemã tem inventado e produzido vale a pena verificar o tempo passa veloz (FOLHA do NORTE, 1934, n. 1280).

O interesse em divulgar os festejos carnavalescos era algo que trazia benefícios ao grupo Folha do Norte, pois aliado à divulgação dos festejos estavam também a divulgação e a propaganda de lojas dos patrocinadores da cidade, como fornecedoras dos elementos indumentários "necessários" ao ato de brincar os dias de Momo. 
Reforçando a ideia de que a festa é movimento e inovação é que as soluções para as "crises" carnavalescas começam a ser traçadas nas páginas dos jornais. Ainda em 1934 começaram a construir a ideias da "solução"; a micareta, que só a partir de 1937 seria conhecida dessa forma, pois em 1934 era conhecida como pascoela carnavalesca. Vejamos como isso começou a ser feito:

\begin{abstract}
Passou breve, fugaz como todas as coisas que proporcionam prazer, o tríduo da Folia. Os folguedos dos primeiros dias de reinado de Momo único decorreram algo frio, pesas da elevada temperatura ambiente. Fizeram-se notadas inconveniências e falhas.

O movimento comercial da tardinha e da noite de sábado afiguraramse a muitas pessoas promissor de extraordinária animação affluencia de foliões a Avenida da Alegria, (denominação dada por experimentando carnavalescos às ruas Conselho Franco e dos Remedios, onde a circulação avulta em dias de carnaval) o que, no entanto, não ocorreu (...). Os momophilos feirenses querem ressarcirse da relativa frieza do carnaval citadino e da quarentena nesta de abstinência, promovendo festa álacre em sábado de aleluia e domingo de Páschoa (FOLHA do NORTE, 1934, n. 1281).
\end{abstract}

Nesse trecho indica a organização de uma festa posterior ao carnaval, com um complemento ao carnaval. Tratou também das falhas que impediram a realização de um festejo satisfatório, isso na percepção do jornal. Mas o principal aspecto é a construção da necessidade de ressarcimento, do anseio em complementar aquilo que não teria alcançado o objetivo esperado. E nisso duas possíveis causas da crise carnavalesca feirense seriam resolvidas: a proximidade com o carnaval soteropolitano e a dificuldade em estabelecer um carnaval dito civilizado.

Ao que parece a prática de festejar o sábado de aleluia não era uma surpresa, visto que a notícia não apresenta isso como uma novidade. Então se tratava de uma invenção de festa a partir de algo que já era familiar ao cotidiano feirense e poderia ser uma solução aos entraves da festa carnavalesca feirense, nos moldes imaginados. E nisso o aspecto fundador "cria uma nova tradição, ele resinifica o que veio antes e 
instituiu uma memória outra" (ORLANI, 1993, p.13). Entendo que a opção por uma nova modalidade carnavalesca como o reconhecimento das fragilidades encontradas no projeto de implantar um carnaval que seguisse um ideal moderno e fizesse apagar a memória de uma festa que recorresse aos hábitos "bárbaros" e "inadequados". E a partir de então o discurso da crise foi intensificado, mas a partir daquele momento utilizado para justificar a existência de uma nova festa.

E alguns grupos carnavalescos já estavam a organizar o novo festejo. Estes aparecem como informativos.

\footnotetext{
O novo e já promissor Bloco dos Farristas realizará festas campestres inclusive a queima de um Judas na Praça da Matriz, que fica próximo a sua sede fará passeata pelas principais artérias da urbe.

Somos informados de que o já festejado Bloco dos Duvidosos também empreenderá attraente diversões nos dois dias mencionado.

Mais um cordão:

Cogita-se da organização de um novo bloco ou cordão que pretende estrear nas próximas festas da Páschoa, vulgarmente chamado de Micarême, no qual figurarão 30 senhorinhas e outros tantos rapazes de nossa sociedade (FOLHA do NORTE, 1934, n. 1281).
}

Os dois primeiros anúncios não seriam o suficiente para definir que essa seria uma prévia da micareta, pois a queima de Judas é algo comum do sábado de Páscoa, porém por estar aliada ao carnaval, é como uma espécie de ação para desencadear outro momento carnavalesco que permite fazer tal afirmação. Esta hipótese é fortificada com o último anúncio, que é a criação de um novo bloco especialmente para a Mi-carême, um clube aparentemente feminino, as Melindrosas, composto por lavadeiras do bairro Tanque da Nação; bairro periférico e fundamentalmente negro da cidade.

A partir da ideia de crise, uma nova festa carnavalesca começava a ser forjada, crise que apresentava inúmeras contradições, inclusive. Sobretudo quando encontro em outros jornais uma narrativa que coloca em dúvida o suposto carnaval feirense

Observemos balanço feito pelo Jornal Folha da Feira sobre o festejo de 1934: 
Carnaval e carnavalescos

O tríduo carnavalesco deste anno foi festejado pelos foliões inveterados.

Domingo, segunda e terça-feira os carnavalescos vieram à rua num completo pandemônio.

Deram notas alegres: Os duvidosos, as Melindrosas, Doutro Planeta e outros grupos esfusiantes.

As Philarmônicas 25 e Euterpe abriram os seus salões para a realização de bailes e phantasias.

Inúmeras caretas encheram a urbe de graça e humor.

Vários automóveis enfeitados deslisaram pelas ruas da cidade.

Apezar dos pezares o carnaval não foi tão friamente como se antecipava.

Várias pessoas adeptas da folia carnavalesca preparavam-se para tomar a frente dos festejos a Momo do próximo ano de 1935 (FOLHA da FEIRA, 1934, n. 281).

Os dois jornais noticiaram o mesmo evento no mesmo período, e os dois apresentam percepções que em alguns momentos chegaram a ser opostas: enquanto o Folha do Norte apontou um fracasso absoluto, um esvaziamento de alegria, o Folha da Feira afirma que foi bastante animado, com as ruas cheias de pessoas e a presença de vários automóveis enfeitados. Nesse ponto voltamos a questão que abre esse artigo; que carnaval que está em crise? Vê-se aqui são duas concepções do momento festivo que nos permite não negar que as crises tivessem ocorrido, mas problematizá-la e pensar que não estamos tratando de homogeneidade.

O panorama festivo dos anos seguinte, no jornal Folha do Norte do ano de 1935, seguiu a mesma lógica de abordar um carnaval em crise cada vez mais acentuada

Moderníssimo e sem o enthusiasmo crescente da multidão folga, decorreu o carnaval nesta cidade. Pode-se afirmar que foi o mais fraco dos Tríduos de Folia.

A bem dizem nem mesmo foi um tríduo, porque no período de tempo decorrido das vinte e duas horas de domingo gordo até as dezesseis horas do ultimo dia de Momo o que ocorreu foi um hiato desconcordante do regime momocrático (FOLHA do NORTE, 1935, n. 1338).

Porém mesmo com o "esvaziamento" provavelmente os grupos que permaneciam na cidade promoviam os festejos carnavalescos: 
Tivemos informações de que certo número de pessoas interessadas pela folia carnavalescas nesta cidade tomou a peito a tarefa de promover meios no sentido de que o rei Momo não passe esquecido entre nós.

Domingo, portanto teremos a cidade vibrar com ruas cheias de graça e encanto, vivendo momentos de verdadeiros delírios. Na segunda e na terça-feira, não menos será a animação dos foliões de toda a espécie carnavalesca, o que nos faz esperar muitas surpresas durante o desejo do tríduo da alegria (FOLHA da FEIRA, 1935, n. 333).

Essa reportagem retomou um momento anterior aos festejos daquele ano, porém verificou-se que uma denominada crise do carnaval não significava o desinteresse geral para com os festejos antecedentes a Quaresma. Segundo a fonte, existiam pessoas organizadas para permanecer na cidade durante a festa e promover os folguedos carnavalescos. O Jornal Folha da Feira quando tratava do mesmo período do, apresentado pelo Jornal Folha do Norte, não apresentava elementos que caracterizava uma suposta “crise", indicava para uma organização que prometia animação.

\begin{abstract}
A Feira amanheceu hotem com a Rua Direita toda enfeitada de bandeirolas e inúmeras máscaras percorreram a cidade, em grupos isolados, destacando-se, pela manhã, um cordão muito bem organizado, composto de gentis senhorinhas que entoaram harmoniosas canções, despertando a gente, como para um alvará de anos (Folha da Feira. Feira de Santana, 4 de março de 1935. Ano VII, $\left.\mathrm{n}^{\mathrm{0}} 344\right)$.
\end{abstract}

Ao analisar as duas reportagens que trataram do mesmo momento festivo, pareceu que eram duas cidades diferentes e na verdade eram. As concepções dos grupos jornalísticos eram diferentes e isso interferiu na forma de ler a cidade, e nesse caso específico o momento festivo. As representações são construídas dessa forma; elas partem de um lugar social e de interesses que organizam o mundo a partir de uma perspectiva (DARTON, 1986)

Enquanto o Jornal Folha do Norte apontou para o não acontecimento dos festejos em alguns momentos dos três dias alegando um esvaziamento da cidade, o 
Jornal Folha da Feira firmou que havia foliões e que estes saíam às ruas. Por esse motivo é a afirmativa de que havia uma "crise" carnavalesca na cidade é perigoso, pois acaba por cristalizar uma única intepretação sobre a cidade e acaba por simplificar as relações, dando respostas lineares e harmônicas para relações que historicamente não ocorrem dessa forma.

\section{Considerações Finais}

A essa altura podemos estabelecer algumas considerações sobre a cidade e a sociabilidade feirense a partir da narrativa de uma "crise" carnavalesca da década de 1930. A primeira delas é relativizar a ideia de crise, pois como vimos em um comparativo com as notícias sobre o carnaval de 1934, os jornais representavam a festa de forma diferente: enquanto o Folha do Norte enfatizada a "crise", o Folha da Feira não apresentava uma narrativa dos esvaziamentos, muito menos do desânimo. Isso me leva a concluir que a "crise" era uma construção narrativa que transformava alguns elementos em protagonistas a ponto de criarem um imaginário de crise do carnaval feirense.

E essa discrepância interpretativa não significa uma farsa ou que devamos escolher uma em detrimento da outra; isso decorre do lugar e dos interesses de quem produz a notícia. E nesse aspecto os interesses do Folha do Norte eram maiores pois seus editores e colunistas estiveram envolvidos na construção de um ideal festivo, a porto de terem representação nas comissões da festa. Lugar que difere daquele ocupado pelo Jornal Folha da Feira, que não tinha essa proximidade com a construção da festa.

E nesse aspecto, a imprensa assume um lugar importante na construção de um imaginário de cidade moderna que necessitava de uma festa adequada aos padrões 
imaginados. Ideal festivo que gestou a ideia da "crise" carnavalesca, que via nos outros carnavais, sobretudo o soteropolitano, uma ameaça aos festejos carnavalescos feirenses, que tentava "vencer", nas palavras do Jornal Folha do Norte, as práticas indesejáveis do entrudo. Associados, ao que pareceu nas reportagens, a uma crise econômica justificada pelos grandes períodos de estiagem e também as reorganizações políticas ocorridas com a tomada de governo por parte de Getúlio Vagas.

Isso nos leva compreender que a "crise" carnavalesca pensada e difundida pelo Folha Do Norte não tinha apenas um motivo, e sim tudo aquilo que pudesse ameaçar um ideal festivo, que envolvia adesão, modos de brincar e toda a pompa e luxo possível. Quando eles defendem a ideia do esvaziamento da cidade nos dias de carnaval acredito que não se trata de esvaziamento demográfico, pois, conforme o próprio Folha do Norte, a festa nunca foi interrompida. Entendo esse "esvaziamento" como a falta de um grupo que promovesse o carnaval aos moldes do idealizado, que era o que ocorria em Salvador e atraia tanto esses foliões, geralmente das elites, para a capital baiana. Nessa perspectiva, a crise representava tudo aquilo que ameaçasse ao projeto de sociabilidade moderna pensada por esses grupos.

Entretanto esse modelo de forma de viver e sentir a cidade teve que negociar com as diversas práticas para conseguir construir um imaginário de cidade moderna e carnavalesca, pois um projeto nunca se estabelece apenas pela imposição; precisa fazer sentido para os sujeitos. E a partir disso entendo que a micareta foi esse ponto de negociação; uma festa criada a partir de um costume da queima do judas e que primeiro passou a ser chamada de pascolea carnavalesca e depois mi-careme e por fim micareta.

Acredito ter sido essa a solução para o projeto que de festa carnavalesca em Feira de Santana; por a micareta ocorrer inicialmente após o domingo de páscoa, ela não 
tinha concorrência com nenhuma outra festa e passara a atrair mais pessoas, o que ajudava a fortalecer a construção festiva. Outro ponto é que por ser uma festa "nova" permitia construir um novo sentido para as coisa, na qual as práticas do entrudo não encontrassem o conforto para se estabelecer; já que isso era comum no período carnavalesco e o que se tinha, com regularidade, a partir de 1937 era a micareta.

Encaro o fato de terem potencializado, sobretudo através da imprensa, um costume de festejos pós quaresma como um reconhecimento do poder do hábito, das formas que as pessoas sentem a cidade e da impossibilidade de implantar um ideal carnavalesco tal qual um decreto. O recuo do investimento de um carnaval ideal precisou se reorganizar e encontrar outros caminhos que incorporassem aquilo que era vivido e logo coberto de sentido e relevância.

A análise desse período e dessas práticas nos dizem muito mais do que apenas os dias de festa, ela torna legível uma cidade, que mesmo enquanto se distrai, não abandona suas estruturas e que mostra como as manifestações culturais são espaços apropriados para uma educação dos grupos sociais; através de narrativas, sobretudo da imprensa, se estabelece quais as formas adequadas de sociabilidade esperam dos sujeitos.

\section{REFERÊNCIAS}

ALENCAR, Hélder. 31 anos de Micareta. Feira de Santana-Ba UEFS, 1968.

ARENDT, Hanna. A condição humana. 13. ed. Rio de Janeiro: Forense Universitária, 2016.

BACZKO, Bronislaw. A imaginação social. In: LEACH, Edmundo et al. Anthroposhomem. Lisboa: Imprensa Nacional/ Casa da moeda, 1985.

BAKHTIN, Mikhail. A cultura popular na Idade Média e o Renascimento: o contexto de François Rebelais. São Paulo: HUCIREC. Brasília: 2013. 
BOURDIEU, PIERRE. Economia das trocas simbólicas. São Paulo: Perspectiva, 2002.

CHALHOUB, Sidney. Cidade febril: cortiço e epidemias na corte imperial. São Paulo: Companhia das Letras, 1996.

CHARTIER, Roger. A História Cultural entre práticas e representações. Rio de Janeiro: Bertrand Brasil, Portugal. Difel. 1990

CHAUÍ, Marilena. Simulacro e poder. São Paulo: Editora Fundação Perseu Abranos, 2006.

CUNHA, Maria Clementina Pereira. Ecos da Folia: uma história social do carnaval Carioca entre v1880 e 1920. São Paulo: Companhia das Letras. 2001.

DARNTON, Robert. O burguês organiza seu mundo: a cidade como texto In: DARNTON, Robert. O grande massacre dos gatos e outros episódios da história cultural da França. 4. Ed. São Paulo: Graal, 1986.

ELIAS, Norbet. O processo civilizador I. 2. ed. Rio de Janeiro: Jorge Zahar. 1994.

FAUSTO, Boris, O crime do restaurante chinês: carnaval, futebol e justiça na São Paulo dos anos 30. São Paulo: Companhia das Letras, 2009.

FOLHA da Feira. Feira de Santana, 19 de fevereiro de 1934, Ano 1934, n. 281.

FOLHA da Feira. Feira de Santana, 25 de fevereiro de 1935, Ano 7, n. 333.

FOLHA da Feira. Feira de Santana, 4 de março de 1935. Ano 7, n. 344.

FOLHA do Norte. Feira de Santana, 7 de Fevereiro de 1931, Ano 21, n. 1125.

FOLHA do Norte. Feira de Santana, Ano 6, n. 209, 14 de fevereiro de 1914.

FOLHA do Norte. Feira de Santana, 31 de janeiro de 1931, ano 22, n. 1124.

FOLHA do Norte. Feira de Santana, 14 de fevereiro de 1931, ano 22, n. 1126.

FOLHA do Norte. Feira de Santana, 21 de fevereiro de 1931, ano 22, n. 1127.

FOLHA do Norte. Feira de Santana, 6 de fevereiro de 1932, Ano 23, n. 1177.

FOLHA do Norte. Feira de Santana, 4 de março de 1933, Ano 24, n. 1233.

FOLHA do Norte. Feira de Santana, 27 de janeiro de 1934, ano, 25, n. 1280.

FOLHA do Norte. Feira de Santana, 17 de fevereiro de 1934, Ano 25, n. 1281.

FOLHA do Norte. Feira de Santana, 9 de março de 1935, ano 26, n. 1338. 
KOSELLECK, Reinhart. Futuro passado: uma contribuição semântica dos tempos Históricos. Rio de Janeiro: contraponto: Ed. PUC-Rio, 2006.

LE ROY LADURIE, Emmanuel. $O$ carnaval de Romans: da candelária à quarta-feira de cinzas, 1579-1580. São Paulo: Companhia das letras, 2002.

NEVES, Frederico de Castro. Getúlio e a seca: políticas emergenciais na era Vargas. Ver. Bra. História. v. 21, n. 40. São Paulo, 2001. Disponível em: https://www.scielo.br. Acesso em: 26 ago. 2019.

ORLANDI, Eni. P. (org.). As formas do silêncio: no momento dos sentidos. 6. ed. Campinas: Editora Unicamp, 2007.

. Discurso Fundador. Campinas: Pontes, 1993.

PESAVENTO, Sandra Jutahy. Cidades visíveis, cidades sensíveis, cidades imaginárias. Revista Brasileira de História. São Paulo. ANPUH, v.27, n. 53, jan-jun. p. 1-13, 2007. Disponível em: https://www.scielo.br. Acesso em: 13 jun. 2016.

Revista Panorama da Bahia, 20 de abril de 1987, Ano 4, nº 80, p. 12.

SANTOS, Vanicléia Silva. Os ritos e os ritmos da micareta no sertão da Bahia. Projeto História. São Paulo, v. 28. Jun 2004. p. 244. Disponível em: http://revistas.pucsp.br. Acesso em: 15 jun. 2013.

SILVA, Aldo José Moraes. De terra sã a berço da Micareta: estratégias constitutivas da identidade social em Feira de Santana. Revista de História Regional, p. 104-133, Inverno, 2008. Disponível em: http://www.revistas2.uepg.br. Acesso em: 02 maio 2013.

SILVA, Miranice Moreira da. Entre máscaras e serpentinas: por uma história dos festejos carnavalescos feirenses (1891-1939). Dissertação de mestrado. Universidade Estadual de Feira de Santana. Feira de Santana, 2013.

\section{Endereço da Autora:}

Miranice Moreira da Silva

Universidade do Estado da Bahia - Campus V

Loteamento Jardim Brasil $\mathrm{s} / \mathrm{n}$.

Santo Antônio de Jesus - BA - 44.570-000

Endereço Eletrônico: miranicem@gmail.com 